\title{
The Role of Big Data in Internet Advertising Problem Solution
}

\author{
K.K. Hashimova
}

Sector chief of the Institute of Information Technology of ANAS

\begin{abstract}
The article highlights Big Data and Internet advertisement problems. It describes the role of Big Data in the Internet advertising, and their interaction. The article explains the development and implementation of the Web-page concept, and evaluation of its effectiveness, as well as the obstacles for the work with Big Data. It thoroughly studies the role of big data in marketing.
\end{abstract}

Index Terms: Big Data, Internet, Web page, Web-server, ETL, information technology, consumer, RTB, marketing, business, economy, advertising.

(C) 2016 Published by MECS Publisher. Selection and/or peer review under responsibility of the Research Association of Modern Education and Computer Science.

\section{Introduction}

As the result of the rapid development of science and technology the data on Internet advertising is increasing dramatically. The prompt expansion of the Internet and information technologies has led to fundamental changes in various fields business, economy, industry and management in many countries.

The question "Who is the foremost customer for me?" concerns all modern companies. Manufacturer has to deliver the information to the customer interested in products and services at suitable location, for affordable price, and at appropriate. When economy suffers from deficiency, the products manufactured according to the customer's. After the emergence of this method the market's revival has been observed.

International organizations of many leading countries also focus on Big databases. The first initiative in this field was put forward by the United States. They were followed by state and government structures of a number of western states, Australia, China, Japan and others. Big databases are estimated as a strategic resource as oil, and became of great importance.

The US have already succeeded in research and development level of Big data and stepped into its implementation phase. It should be noted that the US presidential administration announced Big Data Research and Development Initiative in March 2012. As part of the initiative, the US administration has allocated 200 million UDS to relevant government agencies (NSF - National Science Foundation, NIH - National Institutes

Corresponding author: K.K. Hashimova

E-mail address: kama25@mail.ru 
Health, DoD - Department of Defense, DOE - Department of Energy, DARPA - Defense Advanced Research Projects Agency and the US Geological Survey USGS) for the use of BD technologies in the state policy and for the organization of multiple events (conferences, forums, etc.), projects, and for the acquisition and analysis of large-scale electronic data. The initiative is designed to develop 84 projects [1]. The initiative is intended to improve new infrastructure and research methodology for Big databases, as well as to improve the ability of using databases for scientific discoveries. The White House expects the use of BD for the following purposes: - developing technologies needed for big data collection, storage, protection, management, analysis and sharing; -mastering these technologies to accelerate the pace of scientific discovery in the fields of science and engineering (technology), to strengthen the national security, and to change education and training radically; - accelerating the training of specialists and new talents in the field of development and use of Big Data technologies. The project also includes to train data scientists and engineers, in particular, analysts with high capacity in the field of text extraction in any language. Specifically, it includes to be applied in the following areas: healthcare and social protection, environment and sustainable development, emergency and disaster response, manufacturing, robotics and intelligent systems, cyber security, transport and energetics, education and human resources development areas. To fully benefit from the opportunities of Big Data, and to make effective use of its potential, state, industrial, academic institutions and non-profit organizations are working together for the implementation of this initiative.

\section{Why Big Data?}

Three main types of Big Data paradigm are distinguished.

$>$ storage and management of data of hundreds of terabytes or petabytes (usually does not allow effective use of relative databases);

$>$ unstructured information, which consists of texts, images, video and other types of data;

$>$ questions arise regarding the types of unstructured information during Big Data analysis, analytical reports generation, as well as application methods of predicted models [2].

According to the experts' assessment, the revenue of Big Data projects market together with the business analytics (BA) market amounted about 100 billion dollars in 2012. This includes the components of network technology, servers, software and technical services.

Big Data technologies are used to guarantee the revenue during the automation of companies' performance. The use of Big Data technologies enables the automation of an enterprise's performance guarantying the income. Advanced systems that guarantee the revenue allow the enterprises to detect losses timely, to analyze the data profoundly, and to clarify inconsistencies or distortion of information. The companies confirming the demand of Big Data technologies in the local market have positive impact on the data growth, quality improvement, and decision making by stimulating Big Data development.

It should be noted that, the overall application of Big Data also depends on the management of marketing in Internet advertising. This management includes [3]:

1) forming active support system of purchase,

2) creating favorable conditions for conducting research and practical and development work,

3) providing shopping facilities with consulting, engineering, technical, technological, information and other services,

4) providing market-related businesses with marketing services,

5) accompanying products and services before their selection and introduction to the production,

6) developing intelligent information system to support decision making, and so on. 
Information used for the management of marketing of the Internet advertising can chiefly be obtained from the following sources:
a) information centers,
b) press, mass media,
c) trade - industrial chamber,
d) statistics committee
e) standardization and metrology committee,
y) ministry of economic development,
k) banks,
r) consulting agencies and others.

Information support system in the management processes of Big data includes several elements [4]: 1) data collection, 2)organizing information turnover, 3) information storage and update, 4) maintenance of information system, 5) mathematical software of information system, 6) information delivery and so on. Applicable management decisions made for sustainable marketing activities of the Internet advertising is ensured by sufficiently providing the organization with appropriate and perfect information.

\section{Interaction Between Data Big and advertising}

The rapid development of information technology at the same time leads to an abundance of information. Therefore, the information collected by most communication means in sales points such as telephone calls, email, events, meetings, registration forms in web sites, advertising links, chats, social networks, and surveys about the customers is stored in a single warehouse [5].

During the interaction with the customer all the necessary information is collected and stored in the database.

Based on the analysis of the data collected about the customers, the demand for these and other products of the company is predicted by dividing the customers into several segments.

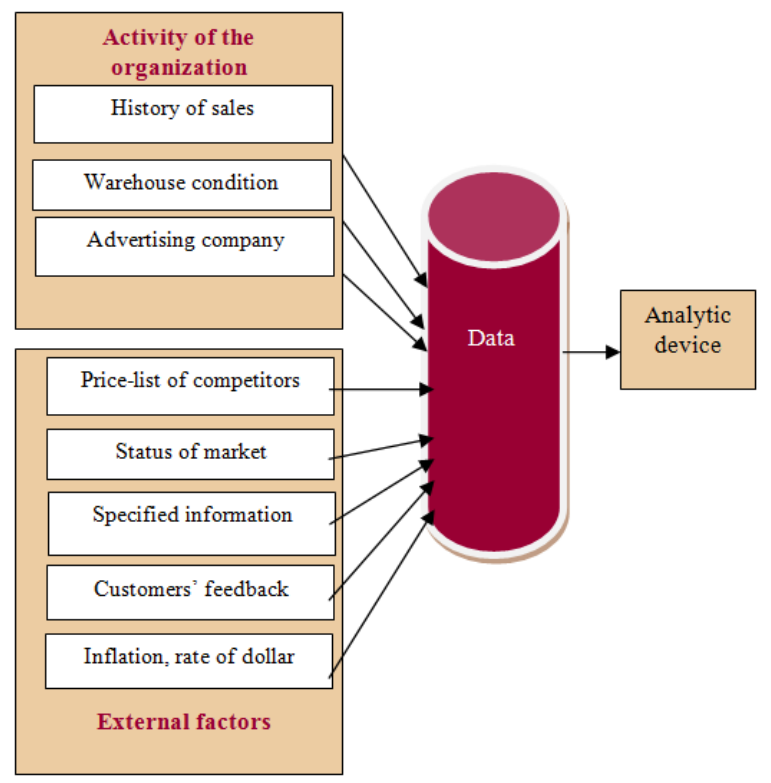

Fig.1. The results of the advertising analysis 
The volume of collected information almost doubles each year, which generates Big Data [6].

Big Data is a storage and management of large amounts of data.

Cloud Computing is gaining popularity, finding the optimal combination of services that are relevant to the user query becomes increasing necessity. The main reason is that the need for the particular type of service is user dependent. Each user has different levels of priority for different services available on the cloud specially with respect to the cost [7].

\section{Selecting Target Segment}

To reach the goal, any company places information about the goods, company or service on a Web page. Therefore, the company is more interested in attracting the users to the Web page. The use of Web sites and marketing strategy allows the company to achieve its targets, and to satisfy the needs of consumers compared to its competitors.

"Big Data" is a set of the large volumes of data obtained in different ways (network, blogs, photos, videos, $\log$ files, etc.), which cannot be processed by ordinary tools. This new term is referred to the data, which cannot be processed in terms of its volume and complexity. Emerging Information Society is experiencing its greatest scientific and technological revolution, and this revolution has penetrated all spheres of the life from business to science. This is also a complex problem from the social, economic, security and scientific aspects. The problem is deepening with the idea of the Big Data. Thus, storage and management of "Big Data", and obtaining marketing information from them has created a serious problem. The problem is existing ineffective IT (Information Technology) solutions, which are used for real-time processing and analysis of data generated automatically and continuously from different sources. As a result, data is extremely easy to be generated and extremely difficult to be processed" [1]. A wide range of opportunities offered by "Big Data" technologies can also be widely used to solve marketing problems of Internet advertising. Solution of information security and data protection are the key issues for "Big Data". The problems include managing large volumes of advertising data, information security, data confidentiality and marketing data protection, access control, audit and realtime monitoring of information security, and so on. "Big Data" technology plays a special role in automatically responding to information security incidents and eliminating their consequences in a short term and minimum costs, and in its in-depth study .

\section{Developing and Implementing the Concept of Web-page}

One of the ways of influencing the clients is placing the advertising and marketing on the Web-page. Presenting the advertisement precisely and correctly is the key term for its long-term success during the development and implementation of the concept of the web page. Therefore, the information presented on the Web page must meet the following criteria:

- $\quad$ must be consistent with the objectives of the Web-page advertisements;

- $\quad$ should take into account the characteristics of the target segment of the consumers;

- $\quad$ must be unique to attract the attention of customers to some extent;

- $\quad$ should be proper to launching;

- $\quad$ should be operational and updated constantly to maintain the interest for the Web page;

- $\quad$ should be objective and reliable, otherwise, the customers detecting inappropriate or imprecise information are unlikely to visit this page again;

- $\quad$ should not be too bothersome [8].

Web-page may include various information about the company and its products, products and services directory, list of the addresses of its dealers, survey data, news, network stores, feedback field, vacancies and so on. Therefore, placing the information on the Web page, which provides the requests of consumers only, is 
more appropriate. One of the main aspects of designing the content for Webpages is the use of technical and entertaining information reflecting the company's features.

As a rule, the furthermost and the most interesting information is placed in the upper part of the first pages of newspaper to draw attention. Such rules must be guided and followed when designing the Web pages.

Keyword search over encrypted data: The most attractive among them is the support for multiple keywords. New approaches still need to be designed to completely preserve the order when summing up scores for all the provided keywords [9].

The observations show that most users pay less attention to the links, pictures and texts in the lower part of the Web-page, and some users are interested in the advertising launched on the screen. Hence, the most important news and all Web-page options should be at the top of the page.

\section{Evaluating the effectiveness of web-page}

The effectiveness of web-page can be measured with two methods:

A) By server statistics and quantitative analysis. The following indicators can be used here:

- number of requests to Web-page

- daily statistics of Web-page user-frequency

- number of individuals reviewed Web-pages

- time of attendance of Web-page

- $\quad$ page slinked to the web-page [10].

B) The analysis of the quality with the following data:

- $\quad$ survey of potential consumers to determine the level of Web-page satisfaction

- level of significance and evaluation of the components, which describes the relevance of the users needs with the Web page(content, design, ease of use, etc.) according to the survey

- $\quad$ studying the responses sent by the Web-page users

Due to the rapid development of the Internet these statements predicts the crucial changes in the marketing principles.

As the Web-server is an important element of the turnover of the goods on the Internet, scheming its economic efficiency is of great importance [11].

Cost-effectiveness of selected options for building e-commerce system of an enterprise based on Web-server in the Internet environment can be defined as the ratio of the result of its application to the costs associated with the development and operation of the system.

$Э=Р \Pi / \Pi 3$

Total costs $\left(\Pi_{3}\right)$

$$
\Pi_{3}=К+Э 3
$$

$\mathrm{K}$ is the total volume of capital investments in the system structure;

Э3 denotes the maintenance costs.

In this case, we have to take into account that the use and application of Web-server is expanding constantly depending on an instant of time. In many countries, it is very low [12]. 
When the company launches its own website it should convey information to the user about the availability of new resources in the network. At this stage, an indication of the advertising effectiveness,

Aware ness coefficient may be the coefficient of the number of users to the quantity of target audience of the Web-site [13].

$$
\text { Ko }=\text { So } / \mathrm{S}
$$

The opportunities of Big Data is considered when evaluating the effectiveness of the data collected on the Web-server.

Big Data provides potential responses by dividing the customers into the segments basing on the results of the data analysis collected about the customers, and predicts the promotion of this or that product of the company. Experts state that the rapid growth of data is a reality. Social networks, mobile devices, and business are the sources generating large-scale information.

IDC Digital Universe report published in 2012 predicts that the amount of data in the next 8 years will reach 40 ZB (zettabyte), which amounts5200 GB per capita throughout the planet.

Most information is generated not only by people, but also by their interaction with one another, and by transmitting the data through sensor and intelligent devices via the network. Researchers predict that, such growth rate in the world will double an amount of data each year. That will lead to the doubled increase in the number of virtual and physical across the world and to the creation of new data centers. The efficient use of this information may be transformed into money. As the use of Big Data requires large investments, the volume of sales should be increased by raising the effectiveness of the business and cutting expenses [14].

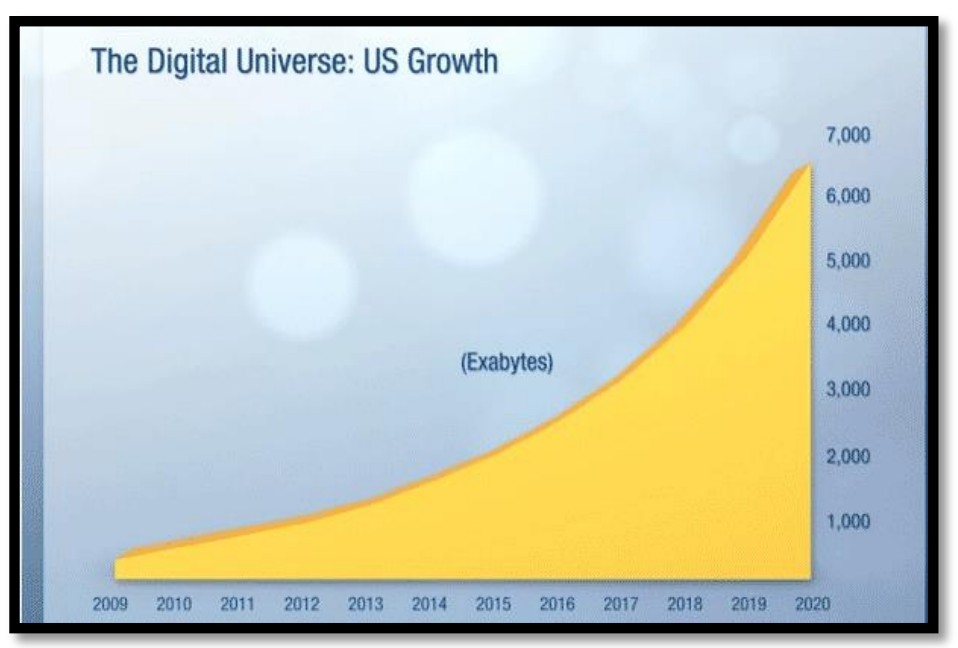

Fig.2. The growth of digital information collected in the United States

\section{What prevents working with Big Data?}

Currently only $0.5 \%$ of the collected digital data analysis and a wide range of industrial issues are solved with the help of Big Data. Sophisticated IT bases process the collected data and evaluate the results. The high cost of projects, and the choice of the data to be processed are the major factors hampering the wide use of Big Data. What information should be appointed, removed, preserved and analyzed is a big problem.

Many business representatives note that most difficulties occurring in the application of Big Data projects are linked to the lack of marketing and analytical experts. Reimbursement of Big Data investment directly 
depends on the quality of the work of the analytical expert. The marketers do not use most of available information, as its outdated business processes.

Big Data projects is not only the business, which is difficult to implement, but the results of the evaluation of the collected data is considered to be complex. Working with the data requires the marketers and analysts to solve technological and specific business issues.

In regard with the high-speed flow of large-scale data, real-time ETL process is offered for data collection [15]. ETL (Extract, Transform, Load) - is one of the key processes that manage data warehouses. It cleaning business model and loading needs for data extraction from external sources in the warehouse, its transformation and compliance. ETL is not only a data transfer process, but also a means of data preparation.

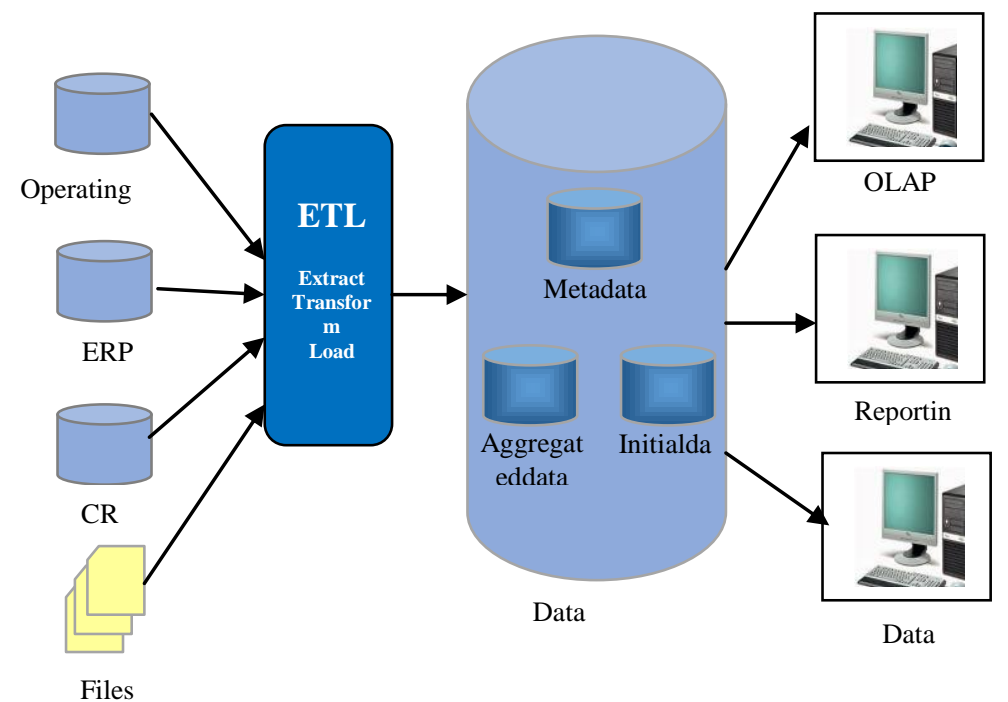

Fig.3. Data transmission process through ETL

Data security in external sources should be resolved in accordance with the volume of collected information. Big Data analysis methods are growing only with the rising volume of data.

Big Data is developing due to the increase in the volume of data. The nature of analytical platforms plays a crucial role in the development of new methods. Information about potential customers or about the history of web-sites of online-stores can be used for the solution of various issues.

Despite all the difficulties regarding the application of Big Data, investments in this area are likely to increase. The research led by E.K. Gartner shows that, available media, telecommunications, banking and service companies are the investment leaders in the field Big Data. Some successful results of Big Data application are used in logistics and assembly systems, as well as loyalty programs, and retail sector with the help of radio frequency identity. According to successful experience, retail market helps to find new effective ways to transform data into money. The costs of various investment projects presented in the field of Big Data have different character.

\section{How it works?}

Numerous software and hardware with a range of opportunities are available to apply effective Big Data solutions in several business areas. For example, social media and mobile applications, intelligent data processing and visualization of business data. The main advantage of Big Data is working with the database cross 
Solution disciplinary projects, which are widely used in business. For example, organization of multichannel sales and customer support is of particular importance.

Russian startup Synqer Simplate platform was developed by processing a large database. It analyzes the following data about the customers in the program, by justifying the processing of big data files:

- date of purchase

- age

- $\operatorname{sex}$

- $\operatorname{mood}[16]$.

E.g. Cosmetic stores install touch screens in the cash office recognizing the emotions of customers. The applications defines the mood of people, analyzing the information about him, sets the time and scan discounts base of the store, and then sends news about special offers and promotions to the customer. This solution increases the customer's loyalty and retail sales.

At Dunkin Donuts company, which uses data for the products sale, changeable offers appears on the digital screens of depending on the part of the day and availability of products basing on the Big Data application

experience. According to the bills in the cash office, the company obtain the information about the offers which attract the customers. This data processing increases the revenue and turnover of the products in the warehouse.

Experience shows that the use of Big Data projects may resolve modern business issues successfully[17]. Choosing the right strategy when working with large-scale information, as well as the proper use of innovation technologies in the field of Big Data is an important factor.

Table 1. Most significant commercial digital marketing trend 2013-2014

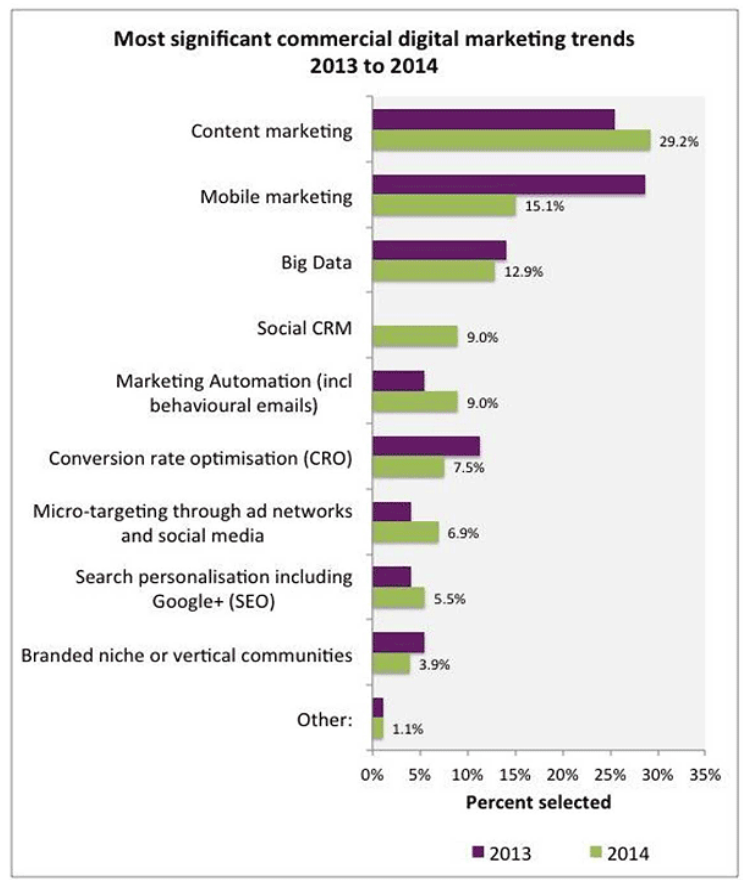


Obviously, Big Data is not so new. Sources of large-scale information already existed many years ago: databases of customer purchases, credit history, lifestyle, etc. Over the years, researchers have used this data to help the companies to assess risks and predict future needs of the customers. However, today the situation has shaped in two aspects:

More sophisticated tools and methods occurred for the analysis and compliance of various data collections;collection and measurement of the digital data, which is anew source of analytical tools[18].

The possible range of information inspire the researchers, and at the same time, its growth in the structured research environment causes some concerns. The sites and different types of social media define the consumption. Not only TV, but also saved digital tags and mobile devices determine the fact of ads review. Behavioral data (number of calls, customer habits and sales) is now available in real-time mode. Therefore, the results obtained with the help of research before now are studied with the help of Big Data. Regardless of any research processes, all information is constantly active, and a question arises. Will these changes replace the classic study of Big Data market?

\section{Big Data in marketing}

Information is a key aspect of successful prediction of the growth and a marketing strategy. For many years, Big Data analysis has successfully served for the target audience, interests, needs, and consumers' activity. Thus, Big Data is the most accurate tool of marketer to predict the future of the company.

For example, big data analysis (based on the popular model of Real Time Bidding) creates opportunities to display ads only for customers who are interested in the product or service.

Big Data application allows businesses the followings:

- getting to know their consumers better, and attracting the identical audience on the Internet;

- $\quad$ assessing the level of customers' satisfaction;

- understanding reliability of the offered service that provides the needs;

- finding new ways and implementing them to enhance the customers' trust;

- developing the projects on demand.

\section{Conclusions}

Turning the data obtained from the analysis results, and the user's behavior and reactions into useful information and evaluating them in real time is a serious competitive advantage [7].

Today, high-tech development rate and huge information flow, and the use of Big Data in the companies creates more opportunities to achieve the highest efficiency.

Big Data is a new generation of technology, which ensures the use of large-scale information. There are software and hardware platforms, such as Map Reduce, Hadoop, HDFS, and NoSQL, which are developed to processing and analysis the data characterized with the features such as its large volume, velocity and variety. However, supercomputers, grid and cloud technology eliminated some certain problems related to large-scale data, there are still strict technical, scientific and theoretical challenges in this field. The problem is not limited with the maintenance and management of large volumes of data, but it also includes unstructured data analysis and results interpretation. A large number of exceptional successes can be achieved in scientific fields in a short term, management and business income may be obtained, and competitive advantages can be gained by achieving perfect Big data analysis.

Increasing the effectiveness of advertising and marketing in the development of the economy, and significant opportunities and role of Big Data are undeniable to reach the goal. 


\section{References}

[1] Apache Hadoop in the cloud using Big Data Processing System, www.researchgate.net.

[2] How to create a website for advertising agency, Laboratory of Advertising, Marketing and Public Relations, No 7/8, 2001.

[3] Ivanov P.D., Lopukhovsky A.G. Big Data technologies and different methods of presenting big data. Engineering Journal: Science and Innovation, 2014, vol. 9. No9 (33).

[4] Alguliyev R.M.,Aliyev A.G, Shahverdiyeva R.O. Development of information support systems for management of innovative structures. The 8th IEEE International Conference on Application of Information and Communication Technologies (AICT2014). Kazakhstan, Astana, 15-17 October 2014. pp. 378-382.

[5] 2015-03-042015-03-04Manual -M. Publishing House "Vilyame" 2000.

[6] AlguliyevR., HajirahimovaM., "Big Data" Phenomenon: Challenges and Opportunities // Journal of Problems of Information Technologies, 2014, No2, pp. 3-16.

[7] GaurV., DhyaniP., Rishi O. P. A GA-Tabu Based User Centric Approach for Discovering Optimal Qos Composition PP.56-62, Pub. Date: 2015-2-8 DOI: 10.5815/ijmecs.2015.02.08.

[8] ZikopoulosPaul C., McGraw H.Understanding Big Data: analytics for enterprise class hadoop and streaming data, 2012.

[9] KaurR., MahajanM., Enhanced Ranking Based Cloud Searching with Improved Metadata Storage: A Case Study for Relevancy of Files PP.40-47, Pub. Date: 2016-1-8 DOI: 10.5815/ijmecs.2016.01.06.

[10] Manual. Edited by Glazyev. -M .: Basics of e-commerce: MSUK, 2001.

[11] Kuritskiy A.B. Internet economy. Spb., 2000.

[12] http://www.mckinsey.com/insights/ business technology/big data the next frontier for innovation.

[13] www.computerworld.com.tr/featured/buyuk-veri-ile-gelen-tasarruf/.

[14] http://rusbase.com/news/big-data-adv/.

[15] http://instam.ru/BIG-Data.

[16] http://lpgenerator.ru/blog/2015/11/17/chto-takoe-big-data-bolshie-dannye-v-marketinge-problemyalgoritmy-metody-analiza/

[17] http://www.marketing.spb.ru/lib-research/methods/Big_Data.htm.

[18] http://lpgenerator.ru/blog/2015/11/17/chto-takoe-big-data-bolshie-dannye-v-marketinge-problemyalgoritmy-metody-analiza/.

\section{Authors' Profiles}

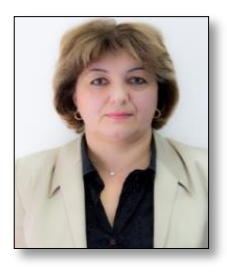

Kamala Kamil Hashimova Currently she is the chief of sector at the Institute of Information Technologies of ANAS.

She closely participated in the creation of "Multimedia Gallery" base of the Institute and currently is in charge there. Participated in the creation of the www.science.az portal of ANAS.

Controls data posting in the section "Institute in mass media" of www.ict.az web-site. She teaches at the Education Center of the Institute. Author has of several papers.

How to cite this paper: K.K. Hashimova,"The Role of Big Data in Internet Advertising Problem Solution", International Journal of Education and Management Engineering(IJEME), Vol.6, No.4, pp.10-19, 2016.DOI: 10.5815/ijeme.2016.04.02 